\title{
EFEKTI INTRANETA NA UPRAVLJANJE ODNOSIMA S INTERNOM JAVNOŠĆU USLUŽNIH ORGANIZACIJA
}

\author{
Jelena Stanković1, \\ Radmila Živković ${ }^{1}$, \\ Jelena Gajićc ${ }^{1}$, \\ Ivana Brdar ${ }^{1}$,
}

${ }^{1}$ Univerzitet Singidunum, Beograd, Srbija

\begin{abstract}
Rezime:
Intranet, kao komunikaciona mreža, pored mogućnosti razmene informacija, ideja i iskustava među zaposlenima, pruža benefite podizanja efikasnosti poslovne saradnje, motivisanja zaposlenih, kao i redukovanja troškova poslovanja, što čini preduslove kvalitetnog servisiranja potrošača. Snažan uticaj procesa digitalizacije, kao i rast potrebe za integrisanom upotrebom resursa, učinili su Intranet mreže veoma važnim za kreiranje svrsishodnih informacija kojima imaju pristup svi zaposleni u organizaciji. Istraživanja pokazuju da su upotrebom Intranet portala uslužne organizacije omogućile svom internom segmentu javnosti, pre svega zaposlenima i menadžmentu, podizanje kvaliteta: (a) interpersonalne i timske komunikacije, (b) koordinisanja individualnih napora i poslovnih aktivnosti koji upotrebom veb-pretraživača, postaju dostupni svim zaposlenima, kao i (c) mogućnost zajedničkog rada zaposlenih na poslovnim projektima. Oslanjanje na pervazivnu informacionu i komunikacionu tehnologiju uslovilo je dizajniranje takvih Intranet strategija koje su usmerene ka podizanju kvaliteta socijalizacije među zaposlenima i između zaposlenih i potrošača, kao i efikasnijem rešavanju kriznih situacija unutar organizacije. U ovom radu izvršena je analiza rezultata istraživanja dizajna i primene Intranet strategija, sa ciljem identifikovanja zajedničkih parametara njihovog dizajna koji bi predstavljali podršku efektivnom upravljanju odnosima s internom javnošću uslužnih organizacija.
\end{abstract}

Ključne reči:

Intranet strategija, odnosi s javnošću, interna javnost, uslužne organizacije.

\section{UVOD}

Dinamični uslovi savremenog poslovanja, pre svega intenziviranje konkurencije i promene potreba i ponašanja potrošača, uslovili su menjanje faktora distinktivnih kompetentnosti organizacija. Kvalitetna usluga danas predstavlja izvor diferenciranja, a time i ostvarivanja konkurentske prednosti na tržištu. Upravo to pred uslužne organizacije postavlja težak zadatak, pre svega identifikovanja novih načina kojima će ona graditi svoju operativnu i komunikacionu efikasnost kao faktore ostvarivanja konkurentske prednosti. Na prvo mesto se može svrstati efikasno pristupanje pravovremenim i svrsishodnim informacijama, neophodnim za podizanje poslovne produktivnosti i kompetentnosti, kao i adekvatno alokaciranje resursa [1], čime se stvaraju preduslovi kvalitetnog servisiranja potrošača.

\section{Correspondence:}

Jelena Stanković

e-mail:

jstankovic@singidunum.ac.rs 
Za razliku od reaktivnog pristupa upotrebi informacija, koji podrazumeva reagovanje na događaje i odsustvo učestvovanja u procesu generisanja informacija, proaktivni pristup podrazumeva aktivno učestvovanje organizacije u stvaranju i upotrebi kreiranih informacija, pre svega u svrhe uvođenja promena i građenja održive inovativnosti u procesu usluživanja potrošača [2].

Mnoge kompanije su shvatile da upotreba Intraneta, kao poslovne strategije, obezbeđuje pristup internim informacijama, pružajući niz prednosti, pre svega ušteda troškova, rasta efikasnosti, stabilinosti i fleksibilnosti poslovanja [3], kao i zajedničkog pristupanja znanju i idejama zaposlenih u organizaciji [4]. Praksa je pokazala da razvoj distinktivnih kompetentnosti uslužnih organizacija leži, pre svega, u upotrebi World Wide Web-a i Intranet mreža u poslovanju, koje omogućavaju upotrebu e-maila, sistema za upravljanje sadržajem, sistema za upravljanje projektima, ključnim za podršku procesima komunikacije, kolaboracije, i operativnih aktivnosti zaposlenih i menadžera, kao internih javnosti organizacije [5].

\section{INTRANET I UTICAJ NA ORGANIZACIJU}

Elektronske mreže za obavljanje komunikacije pre svega obuhvataju Intranet i Extranet, kao specifične komunikacione mreže bazirane na razvoju i primeni Internet tehnologije. Extranet omogućava autorizovanim korisnicima, a to su zaposleni i menadžerska struktura, da komunciraju sa spoljnim javnostima kao što su potrošači, dobavljači, finansijske institucije i drugi partneri na tržištu. Kompanija Harley-Davidson razvila je Extranet, obezbedivši zaposlenima brzu i jednostavnu komunikaciju sa angažovanim dilerima i partnerima koji obavljaju distribuciji njihovih proizvoda širom sveta [6].

Intranet, sa druge strane, predstavlja komunikacionu mrežu kojoj isključivo imaju pristup zaposleni u organizaciji. Ona obezbeđuje uklanjanje vremenskih i prostornih barijera u komunikaciji unutar organizacije, čineći razmenu informacija efikasnijom i efektivnijom. Mnoge organizacije uspostavile su Intranet komuniciranje, kako bi zaposlenima omogućile razmenu ideja, iskustava, rešenja problema, isprobanih servisnih receptura, kao i brži i kvalitetniji zajednički rad na programima i projektima. Intranet komunikacioni sistemi podstiču razvoj menadžmenta znanja (knowledge management), kao osnove donošenja upravljačkih odluka u organizaciji, budući da omogućavaju sprovođenje sledećih koraka svog strateškog razvoja [7]:

- Identifikovanje znanja korisnog za kompaniju
- Intranet omogućava zaposlenima dolaženje do odgovora na sledeća pitanja: Kakvo je znanje potrebno organizaciji? Iz koje oblasti poslovanja? Gde se nalazi to znanje? Ko ga poseduje? Kako se ono može korisno upotrebiti?

- Prikupljanje znanja u formi izveštaja, studije ili nekog sličnog dokumenta - Velike kompanije, među kojima je i Seven-Eleven, elektronskim putem, više puta dnevno, prikupljaju izveštaje o obavljenom poslovanju ili planovima za buduće poslovanje.

- Evaluiranje znanja - Intranet omogućava procenu korisnog znanja, svrsishodnog donošenju poslovnih odluka: Gde i kako se znanje može najbolje primeniti u organizaciji? Šta takvo primenjeno znanje može doneti kompaniji? Da li se to znanje može menjati i prilagođavati, tako da postane šire upotrebljivo?

- Zajedničko korišćenje znanja u kompaniji, plasiranjem izveštaja na Intranetu, ili nekom sličnom mediju. Dobar primer je ideja formiranja ShareNet-a, inovativnog sistema namenjenog jednostavnom pristupu idejama, prikupljanju znanja i iskustava zaposlenih u kompaniji Siemens, a koja pristižu iz svih delova organizacije, proizvodnih i marketinških poslovnih jedinica ove kompanije, smeštenih u celom svetu [8].

Uticaj Intraneta na poslovanje organizacije uključuje dve ključne oblasti. Prva oblast uticaja odnosi se na podizanje poslovne efikasnosti i efektivnosti, što se ogleda u pravovremenom donošenju odluka, agilnosti organizacije kao sistema, rastu kreativnost i lakšem uočavanju šansi na tržištu [9], kao i u redukovanju troškova poslovanja i povećanju prihoda organizacije.

Druga oblast uticaja Intraneta odnosi se na podizanje efikasnosti i kvaliteta komunikacije i saradnje među internim javnostima, pre svega među zaposlenima, kao i između zaposlenih i članova menadžerske strukture [10].

Uslužne organizacije i sistemi su upravo u prilici da koriste navedene benefite Intranet strategije. Najveća švajcarska univerzitetska bolnica Inselspital, smeštena u Bernu, zapošljava preko šest hiljada lekara, administrativnog i pomoćnog osoblja. Budući da predstavlja pravi "grad u malom", menadžment ovog bolničkog megacentra odlučio je da razvije i uvede u poslovanje privatnu Intranet mrežu, koja će obezbediti brzu i kvalitetnu komunikaciju bolničkog, administrativnog i pomoćnog osoblja, menadžmenta i pacijenata. Baze podataka sadrže detaljne podatke i informacije o svakom pacijentu, koje se nakon svakog pregleda redovno ažuriraju i kojima 
se pristupa unošenjem osnovnih podataka o pacijentu (ime, prezime, identifikacioni broj pacijenta). Bolničko osoblje, lekari i medicinske sestre trenutno pristupaju podacima, kontinuirano se informišu o poslovnim aktivnostima, a omogućeno im je neprekidno razmenjivanje ideja i sugestija. Pacijenti nisu u obavezi da sa sobom nose medicinsku dokumentaciju, već se samo koncentrišu na lečenje i oporavak [11].

\section{INTRANET I INTERNI ODNOSIS JAVNOŠĆU}

Pored komunikacionih tokova, Intranet obezbeđuje zaposlenima učestovanje u poslovnim aktivnostima, praćenje i beleženje njihovog doprinosa poslovanju, razmenu dobrih iskustava, $i$ to pre svega putem e-maila, foruma i veb-publikacija.

Prednosti upotrebe Intranet mreže, koje vode podizanju efikasnosti i operabilnosti internih javnosti organizacije, mogu se svrstati u sledeće [12]:

- informacije u vezi sa razvojem ponude (proizvoda i/ili usluga) i planiranja marketinškog nastupa postaju racionalizovane, objektivizovane, dostupne i pravovremene, doprinoseći bržem usmeravanju poslovnih aktivnosti ka ciljnim tržištima;

- redukovanje troškova kroz ostvarivanje veće produktivnosti poslovanja, kao i putem ušteda: a) fizičkog materijala, u slučaju proizvodnih preduzeća, i b) angažovanja radne snage, što je posebno značajno za uslužna preduzeća, budući da su u njihovom slučaju ovi troškovi visoki jer se radna snaga angažuje bez obzira na nivo tražnje za uslugama [13];

- pružanje boljeg ukupnog servisa potrošača, pre svega kada su u pitanju uslužne organizacije čija je primarna ponuda neopipljivog karaktera [13]; varijabilnost usluge čini je teško podložnom procesu standardizacije; objektivizacija informacija prikupljenih putem Intranet mreže, njihova ciljanost i svrsishodnost, pruža dragocenu podršku naporima usmerenim ka standardizaciji usluga, a time i podizanju efikasnosti uslužnog procesa, $\mathrm{i}$

- distribucija informacija svim delovima preduzeća, udaljenim predstavništvima i kancelarijama na nacionalnom, regionalnom $\mathrm{i} /$ ili globalnom nivou.

Motivacija zaposlenih predstavlja osnov njihovog zadovoljstva, i, u slučaju uslužnih preduzeća, direktno se reflektuje na građenje odnosa sa potrošačima. Praksa je pokazala da podizanje kvaliteta internih poslovnih operacija i komunikacije među zaposlenima vodi stvaranju zadovoljstva i motivisanosti zaposlenih. Oni se trude da podižu kvalitet svoga poslovanja i kvalitetnije uslužuju potrošače što dalje vodi rastu zadovoljstva potrošača, njihovom zadržavanju, građenju njihove profitabilnosti, ali i profitabilnosti uslužne organizacije [14]. Građenje internih odnosa s javnošću aktivno utiče na pripremanje zaposlenih za prihvatanje nastupajućih promena u organizaciji, kao i na jačanje korporativne kulture.

Prema Wilkoks i saradnicima [15] interna komunikacija i građenje internih odnosa s javnošću posebnu važnost imaju u situacijama kao što su:

- krizne situacije u organizaciji;

- periodi uvođenja promena, posebno kada su u pitanju restrukturiranja, uvođenje novih poslovnih koncepata i novih tehnologija u poslovanje organizacije;

- kreiranje i održavanje odnosa sa medijima;

- procesi spajanja sa drugim preduzećima ili preuzimanja od strane drugih preduzeća;

- periodi otpuštanja zaposlenih i upravljanja gubitkom radnih mesta;

- periodi tokom i nakon značajnih promena na tržištu (pojava konkurenata, gubitak tržišnog učešća i sl.);

- periodi lansiranja promotivnih kampanja koje su od ključne važnosti za poslovanje preduzeća jer predstavljaju početak novih poslovnih aktivnosti organizacije;

- kreiranje odnosa sa finansijskom javnošću;

- kreiranje odnosa sa lokalnom zajednicom i drugim stejkholderima.

Uspostavljanje efikasne komunikacije u organizaciji posebno je važno tokom sledećih situacija u okviru upravljanja odnosima s internom javnošću: (1) u periodu uvođenja novih zaposlenih u radni proces i njihove socijalizacije, upoznavanja sa profilom kompanije, organizacionom kulturom i načinom komunikacije; (2) u situacijama kada do zaposlenih treba da pristižu aktuelne informacije o efektima poslovanja organizacije kao celine, (3) u periodima organizovanja specijanih događaja i nagrađivanja zaposlenih kao što su premije, penzije, kompenzacije, i priznanja, kada je spomenute aktivnosti neophodno blagovremeno najaviti, i (4) u trenutku prestanka zaposlenja zbog bolesti, tokom reorganizacije, otpuštanja viška radne snage ili odlazaka u penziju. U svim spomenutim slučajevima interna komunikacija mora biti planski sprovedena i u potpunosti usaglašena sa korporativnom kulturom. 
Upravljanje internim odnosima s javnošću podrazumeva komunikaciju formalnim i neformalnim putem. Formalnu komunikaciju usmerava menadžment organizacije, i ona obuhvata lične kanale komunikacije (sastanci, brifinzi, prezentacije), pisane kanale komunikacije (interne novine, dopisi, godišnji izveštaji, plakati) i elektronske kanale komunikacije, te Intranet treba posmatrati kao ključni medij formalne komunikacije.

Kada su u pitanju elektronski kanali formalne komunikacije, organizaciji na raspolaganju stoje sledeći servisi Intraneta koji će doprineti rastu efikasnosti i ekonomičnosti poslovanja, kao i motivaciji i socijalizaciji zaposlenih [5]: a) Intranet pretraživači koji služe za komunikaciju unutar organizacije, putem e-maila, govorne pošte i faksa, i b) tzv. intranet groupware, odnosno klase kompjuterskih programa koji omogućavaju pojedincima da timski ostvaruju ciljeve i uključuju servise kao što su diskusione grupe, čet, audio i video konferencije. Groupware predstavlja softver namenjen uspostavljanju kolaboracije unutar timova i radnih grupa, pri čemu se saradnja među članovima uspostavlja bez obzira na prostor i vremensku zonu u kojoj se zaposleni nalaze.

\section{ANALIZA DIZAJNA INTRANET STRATEGIJA I UTICAJ NA INTERNU JAVNOST}

Istraživanja pokazuju da se uvođenje Intranet strategije i prilagođavanje njegovog dizajna konkretnim potrebama finansijski isplati organizacijama. O'Brien i Marakas [5] navode da, u najvećem broju slučajeva, efektivnost Intraneta opravdava troškove njegovog uvođenja, te da se ulaganja mogu isplatiti u relativno kratkom vremenskom periodu.

Istraživanje efekata Intranet strategija [9] pokazalo je da savremene uslužne organizacije prepoznaju Intranet kao medij koji direktno utiče na poboljšanje komunikacije među zaposlenima, kao i između zaposlenih i menadžera, jer obezbeđuje pristup i razmenu, ne bilo kakvih, već ciljanih, svrsishodnih informacija, ideja, znanja, kao i socijalizacije među zaposlenima, bez obzira da li se radi o zaposlenima koji su se tek uključili u poslovanje, ili onima koji u njoj već rade.

Međutim, rezultati ankete sprovedene u šest javnih preduzeća u Srbiji, od toga dva uslužnog tipa, „Pošta Srbije” i „Telekom Srbija”, pokazali su da je upotreba Intraneta u poslovanju organizacija u Srbiji veoma mala, te da Intranet mreže još uvek ne predstavljaju podršku razvoju elektronskog poslovanja u ovim preduzećima [9]. Svoj stav ispitanici su argumentovali sledećim tvrdnjama: (a)
Intranet se u veoma maloj meri koristi u svrhe razmene informacija i znanja među zaposlenima u organizaciji, i (b) veoma retko se koristi za prikupljanje informacija o potrošačima, kao i za edukovanje zaposlenih u vezi sa upotrebom tih informacija. Istražujući važnost elektronskog poslovanja u savremenom uslužnom sektoru, autori zaključuju da je razvoj Intranet strategije od izuzetne važnosti za opstanak organizacija u Srbiji. Intranet pruža podršku procesima inovacija u organizaciji, kao i interaktivnoj edukaciji među internim javnostima i podizanju nivoa ekspertize zaposlenih [9].

Sa druge strane, istraživanje sprovedeno u svrhe pružanja usluga informacionih tehnologija [3] pokazalo je da Intranet strategije, koje dovode do poboljšanja poslovnih performansi i komunikacije među internim javnostima, treba da uključuju sledeće aktivnosti: promovisanje ciljeva Intraneta u svim delovima organizacije kako bi se zaposleni upoznali sa njima; preciziranje uloga i odgovornosti zaposlenih zaduženih za funkcionisanje Intraneta; upravljanje znanjem prikupljenog u organizacionim procesima; brz i jednostavan pristup informacijama; brendiranje Intranet mreže i njeno povezivanje sa korporativnom kulturom; izbor Intranet alata; ažuriranje i nadzor sistema, kao i pristupanje mreži sa udaljenosti.

Takođe, istraživanja su pokazala da, počevši od 2009. godine, savremene organizacije sve intenzivnije uvode tzv. socijalni Intranet (Social Intranet) [16], koji podrazumeva Intranet mrežu koja omogućava pristup društvenim mrežama koje zaposlenima stoje na raspolaganju kao sredstvo kolaboracije i deljenja znanja sa ostalim zaposlenima. Groupware, kao kolaborativna mreža, svoje uporište i punu mogućnost primene upravo nalazi u prednostima koje pruža socijalni Intranet.

Navedena istraživanja ukazala su na određene zajedničke karakteristike koje, u svrhe razvoja Intranet strategije i njene primene, uslužnim organizacijama mogu pružiti najveću efikasnost i efektivnost:

- Determinisanje i promovisanje ciljeva Intraneta u svim delovima organizacije, predstavlja ključan strateški korak, conditio sine qua non razvoja Intranet strategije, budući da (a) ciljevi Intranet mreže treba da budu usklađeni sa ostalim ciljevima organizacije; (b) implementacija tehnologije i pravila korišćenja Intraneta treba da su, takođe, usklađeni sa potrebama zaposlenih u organizaciji, i (c) zaposleni moraju biti upoznati sa uvođenjem Intraneta, što je ujedno i deo procesa njihove socijalizacije i građenja odnosa sa internim javnostima (zaposleni i menadžeri). Raeth i Smolnik [17] ističu da Intranet igra posebno 
značajnu ulogu u procesima socijalizacije zaposlenih koji su tek pristigli u organizaciju [18]. Prema ovom istraživanju, u informacionom smislu „pridošlice” su spore u pribavljanju informacija koje će postaviti i podeliti na Intranetu, dok su u komunikacionom smislu efektivne u procesu pretraživanja već postojećih sadržaja, budući da nastoje da se što brže prilagode novom okruženju, a što treba imati u vidu prilikom dizajniranja Intranet strategije uslužnih organizacija.

- Komunikacija i upravljanje znanjem predstavljaju aktivnosti koje podržavaju razvoj produktivnih radnih mesta na kojima zaposleni razvijaju distinktivne kompetentnosti organizacije i pružaju svoj doprinos putem dobrih poslovnih ideja. Direktno uključivanje zaposlenih u komunikacione procese, učestvovanje u diskusijama i debatama, sučeljavanje ideja na dobrobit organizacije, postaju najdragoceni pristup socijalizaciji i motivisanju zaposlenih, posebno onih koji su se tek uključili u proces rada. U tom smislu, Roshan i Rao [3] predlažu sledeće oblike internog komuniciranja: saopštavanje ciljeva i strategija organizacije; zajednički pristup informacija o prošlim i nastupajućim događajima, vestima i pričama o poslovnim uspesima organizacije, čime se podiže radni moral; najavljivanje inovacija u ponudi proizvoda i usluga; plasiranje poruka u vezi sa operativnim procesom, kao i o događajima sa "prve linije” usluživanja. U prilog navedenom govori i jedan od rezultata istraživanja sprovedenog u javnim uslužnim preduzećima u Srbiji, prema kojem se šansa da zaposleni postanu demotivisani povećava ukoliko menadžment organizacije ne obrati pažnju na informacije koje su zaista i potrebne zaposlenima. Naime, ukoliko se zaposlenima dostavljaju isključivo bazične i cirkularne ali ne i dovoljno personalizovane, svrsishodne informacije, zaposleni neće imati osećaj da su takve informacije od koristi u operacionalizaciji njihovih poslovnih aktivnosti. Takođe, nedovoljno uključivanje samih zaposlenih u procesu dizajniranja Intranet strategija i poslovnih sadržaja neminovno vodi slabljenju komunikacije i sa internim (zaposleni i menadžeri) i sa eksternim javnostima organizacije (pre svega klijenti i potrošači) [9], budući da motivisanost zaposlenih naglo pada. Upravo zbog navednog, jedna od preporuka sprovedenog istraživanja ističe da razvoj Intranet portala treba da omogućiti potpunu slobodu razmene informacija i znanja među zaposlenima, ma gde se oni fizički nalazili, u kojem god delu organizacije da obavljaju svoje poslovne aktivnosti. Upravljanje pravovremenim, svrsishodnim informacija, kojima će pristupati i deliti ih zaposleni putem Intraneta, podrazumeva formiranje korisne baze znanja koja uključuje četiri elementa, i to su: ljudi, procesi, sadržaji i tehnologija. Navedeni elementi ujedno predstavljaju i bazu kreiranja uslužne ponude [13]. U prilog tome govore i rezultati primene socijalnog Intraneta [16], čija baza komunikacije uključuje ljude (zaposlene na prvoj liniji usluživanja, menadžere i izvršne direktore), procese (upravljanje sadržajima) i tehnologiju (blogovi, komentari, forumi itd.).

- Konstantno ažuriranje i inoviranje Intranet mreže i njenih sadržaja čini važan element dizajniranja Intranet strategije, a koji se direktno odražava na upravljanje odnosima sa internom javnošću. U slučaju da se podaci i alati koje Intranet koristi pravovremeno ne ažuriraju, raste rizik upotebe zastarelih informacija i pucanja linkova, što može dovesti do rasta nezadovoljstva zaposlenih, gubitka poverenja u Intranet, kao i do njegovog spontanog napuštanja. Savremene organizacije na evropskom tržištu, među kojima je veliki broj uslužnih, uspešno razvijaju socijalne Intranet mreže [16], prilagodivši tako komunikaciju među zaposlenima njihovim realno naraslim potrebama i navikama. Socijalni Intranet ovih organizacija uključuje blogove (75\% preduzeća u Evropi), wiki (61\% preduzeća), diskusione forume (65\% preduzeća), komentare korisnika (60\% preduzeća) i društvene mreže, potpuno se bazirajući na tekovinama savremenog digitalnog marketinga i komunikacija. Telindus studija sprovedena na hiljadu zaposlenih Evropljana [16] pokazala je da bi čak 39\% zaposlenih, starosti između 18 i 24 godine, razmotrilo napuštanje firme, ukoliko im poslodavac ne bi omogućio pristup društvenim mrežama kao što su Facebook i YouTube, dok je još 21\% njih naglasilo da bi im tako nešto veoma zasmetalo.

\section{UMESTO ZAKLJUČKA}

Analiza tri studije praktične primene Intraneta u poslovanju ukazala je na zajedničke tačke koje mogu pomoći u procesima dizajniranja Intranet strategija, i koje bi aktivnosti upravljanja odnosa sa internom javnošću 
učinile efikasnijim i efektivnijim. Neosporni doprinos Intraneta komunikaciji, kolaboraciji i koordinisanju aktivnosti u organizaciji ostaje aktuelan, pri čemu će uslužne organizacije morati da usmere dodatne napore na inoviranje važnih aspekata svoga poslovanja, a to su pre svega ljudi, procesi i tehnologija. Uvođenjem socijalnog Intraneta ne samo da je moguć pristup informacijama, bez obzira na ograničenja u vezi sa lokacijom zaposlenih i njihovim radnim vremenom, već je način zajedničkog pristupanja i upotrebi informacija i znanja zasnovan na upotrebi društvenih mreža, prilagođen promenama u potrebama i navikama u komunikaciji savremenih internih javnosti. Dizajn Intranet strategije uslužnih organizacija, baziran na navedenim karakteristikama, direktno će uticati na rast poslovnih performansi zaposlenih, razvijati njihovo interesovanje i poverenje u organizaciju, podižući stepen njihovog zadovoljstva i zadržavanja u organizaciji, što svakako čini osnov kvalitetnog usluživanja potrošača.

\section{LITERATURA}

[1] P.F. Drucker, Management Challenges for the 21th Century, New York: Harper Business, 1999.

[2] J.J. Mohr, S.J. Sarin, „Drucker's insight on market orientation and innovation: implications for emerging areas in high-technology marketing" in Journal of the Academy of Marketing Science, Springer 2009. http://scholarworks.boisestate.edu/ cgi/viewcontent.cgi? article $=1002 \&$ context $=$ market ing_facpubs mart 2017

[3] D. R. Roshan, K.S. Rao, "Intranet Design Strategies", International Journal of Electrical and Computer Engineering, no.3 vol. 6, pp. 936-944., 2016.

[4] M. Edenius, J. Borgerson, "To manage knowledge by intranet", Journal of Knowledge Management, vol/issue 7(5), 2003., pp. 124-136

[5] O'Brien, J., Marakas, G.M. Management Information Systems, 7/e, Northern Arizona University, 2006. https://www.coursehero.com/file/p2urcdh/ Answers-Substantial-cost-savings-can-arise-because-applications-that-use-the/ mart 2017

[6] S.P. Robbins, M. Coulter, Management, Upper Saddle River NJ: Prentice Hall, str. 298., 2003.

[7] J. Thompson, "Transformation is job one", New York Stock Exchange: NYSE magazine, i2, str. 20., 2000.

[8] A.D. MacCormack, S. Volpel, K. Herman, „Siemens ShareNet: Building a Knowledge Network“, HBS Case Collection, 2002.
[9] B. Kolarić, R. Petrović, S. Radojčić, "Application of E-Business in Modern Operation of Public Companies in Serbia", International Journal of Business Administration, vol. 2 no. 3, str. 34., 2011. prema G. Jacoby, Luqy, "Intranet Portal Model and Metrics: A Strategic Management Perspective", IEEE, IT Professional 7(1), str. 37-44, 2005. http://dx.doi. org/10.1109/MITP.2005.1407803 mart 2017.

[10] http://www.prescientdigital.com/articles/intranetarticles/the-business-value-of-intranet-2.0- mart, 2017.

[11] J. Stanković, Upravljanje promenama u odnosima sa potrošačima u maloprodajnom poslovanju, doktorska disertacija, Beograd: Ekonomski fakultet, str. 135., 2009.

[12] D. Gilbert, Retail Marketing Management, Pearson Education Limited, Harlow, England, str. 72., 2003.

[13] J.E.G. Bateson, K.D. Hoffman, Marketing usluga, Beograd: Data Status, 2011.

[14] J. Egan, Relationship Marketing, Essex England: Pearson Education Limited, fig. 6.7, str. 145., 2004.

[15] D.L. Wilkoks, G.T. Kameron, F.H. Olt, V.K. Ejdzi Odnosi s javnošću, Beograd: CID Ekonomski fakultet, 2006.

[16] T. Ward, "The Social Intranet", The Social Intranet Report, Prescient Digital Media, 2012.

[17] P. Raeth, S. Smolnik, "Antecedents and consequences of corporate weblog usage in the intranet: A process perspective" System Sciences (HICSS), 43rd Hawaii International Conference on IEEE, 2010.

[18] L.E. Chang, S.P. Lin, "Newcomers' socialization by Intranet system", Computer and Information Science (ICIS), 2011 IEEE/ACIS 10th International Conference on IEEE, u Kolarić, B., Petrović, R., Radojčić, S. (2011), "Application of E-Business in Modern Operation of Public Companies in Serbia", International Journal of Business Administration, no. 3 vol. 2, str. 936., 2011.

[19] D. Sirota, L.A. Mischkin, I.M. Meltzer, "Stop demotivating your employees!" Harvard Management Update, 11(1) str.3-6. 2006., u B. Kolarić, R. Petrović, S. Radojčić, "Application of E-Business in Modern Operation of Public Companies in Serbia", International Journal of Business Administration, no. 3 vol. 2, str. 34., 2011.

[20] G. Eason, B. Noble, and I.N. Sneddon, "On certain integrals of Lipschitz-Hankel type involving products of Bessel functions," Phil. Trans. Roy. Soc. London, vol. A247, pp. 529-551, April 1955. (references) 